\section{HUMANASE SOCIAIS \\ V.8・N.2 • Agosto/Setembro/Outubro - 2019 \\ ISSN Digital: 2316-3801 \\ ISSN Impresso: 2316-3348 \\ DOI: 10.17564/2316-3801.2019v8n2p171-184}
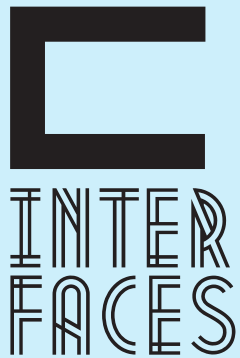

CIENTÍFICAS

\title{
O CAMPO DE PRODUÇ̃̃O CULTURAL E O ESPAÇO DE ATUAÇ̃̃OO DAS MULHERES NO TEATRO LGBT
}

\section{THE CULTURAL PRODUCTION FIELD AND THE WOMEN'S SPACE IN THE LGBT THEATER}

\section{EL CAMPO DE PRODUCCIÓN CULTURAL Y EL ESPACIO DE ACTUACIÓN DE LAS MUJERES EN EL TEATRO LGBT}

Camila Karla Grillo

Ricardo Lanzarini

\section{RESUMO}

Este estudo tem como objetivo discutir as tensões internas e externas do campo, conceito de Pierre Bourdieu, sobre a perspectiva do teatro LGBT, as disputas entre as diferentes identidades e a ocupação na cadeia de trabalho que revelam o binarismo homem/mulher nas produções culturais. Para tanto, apresenta-se um estudo de caso, com aplicação do método de pesquisa exploratória/comparativa, de cunho qualitativo, servindo-se do Guia Gay São Paulo como banco de dados. A análise abarca a coleta dos dados de 22 sinopses de espetáculos teatrais executados em 2018, com temáticas LGBT, e traz a comparação entre quantidade de autores (as), diretores (as) e atores/atrizes na cadeia de trabalho. Como resultado, a amostra revela uma hegemonia masculina no campo de produção do teatro LGBT em detrimento da ocupação de espaço de pertencimento de mulheres héteros e lésbicas.

\section{PALAVRAS-CHAVE}

Bourdieu. LGBT. Mulheres. Teatro. 


\section{ABSTRACT}

The objective of this study is to discuss the internal and external tensions around the concept of Pierre Bourdieu. It gives a perspective of LGBT theatre, highlighting the disputes and occupations in this field of work, and reveals the binary woman/man in cultural productions. The report presents a case study with applications and methodology involving explorative research/comparisons of qualitative product, being developed from data from the "Guia Gay São Paulo." The analysis contains the information of 22 synopses of theatre spectacles presented in 2018 with the LGBT as theme and brings the comparisons between the quantity of female and male authors and actors in the work force. The results from this sample revealed a masculine hegemony in the field of the LGBT theatre productions with detriment to the space belonging to women and lesbians.

\section{KEYWORDS}

Bourdieu. LGBT. Women. Theater

\section{RESUMEN}

Este estudio tiene como objetivo discutir las tensiones internas y externas del campo, concepto de Pierre Bourdieu, sobre la perspectiva del teatro LGBT, las disputas entre las diferentes identidades y la ocupación en la cadena de trabajo que revelan el binarismo hombre / mujer en las producciones culturales. Para ello, se presenta un estudio de caso, con aplicación del método de investigación exploratoria / comparativa, de cuño cualitativo, sirviéndose del Guía Gay São Paulo como base de datos. El análisis abarca el levantamiento de los datos de 22 sinopsis de espectáculos teatrales ejecutados en 2018, con temáticas LGBT, y trae la comparación entre cantidad de autores (as), directores (as) y actores / actrices en la cadena de trabajo. Como resultado, la muestra revela una hegemonía masculina en el campo de producción del teatro LGBT en detrimento de la ocupación de espacio de pertenencia de mujeres héteros y lesbianas.

\section{PALABRAS CLAVE}

Bourdieu. LGBT. Las mujeres. Teatro. 


\section{INTRODUÇ̧̃̃o}

As disputas por espaços pertencentes às identidades homem/mulher tem feito parte da história ao longo dos séculos. "A inclusão dos diversos grupos sociais no plano político legislativo a partir do século XX revela um avanço dos Estados em construir processos democráticos mais sólidos e participativos" (RESENDE e EPITÁCIO, 2017, p. 63). Porém, a busca por direitos equiparados continua em pauta, no início do século XXI, com o levante dos discursos feministas, devido à polarização política na sociedade brasileira, que revela um cenário de desigualdade entre as diferentes identidades. Esta tensão, vivenciada e refletida em distintas instâncias reguladoras também se reproduz no campo de produção cultural, com trabalhos que abordam temáticas da vida cotidiana e dos conflitos sociais, a exemplo do teatro LGBT.

Dentro das produções culturais, este segmento tem ganhado destaque nas salas de teatro ao abordar a realidade vivenciada pelas identidades que englobam a diversidade. Entretanto, não se pode deixar de considerar as disputas decorrentes no campo cultural, que aqui terá um recorte e será denominado como campo do teatro LGBT para abordar apenas as peças teatrais com dramaturgias sobre este universo. É nessa estrutura que as tensões marcam as disputas internas e externas do campo, por meio das tomadas de posição dos agentes. Para Pierre Bourdieu (2004) "todo campo [...] é um campo de forças e um campo de luta para conservar ou transformar esse campo de forças" (BOURDIEU, 2004, p. 22-23).

Tratando-se do campo do teatro LGBT, entre as disputas internas, estão as diversas identidades de gênero que nem sempre são representadas, a exemplo da mulher lésbica. Esse contexto apresenta as disputas dentro desse campo que mantêm a legitimação e hegemonia de determinadas identidades em detrimento de outras, ainda que aparente uma unidade que luta por direitos sociais. De forma mais ampla, não apenas as disputas internas, no que tange às temáticas LGBT, aparecem nessa discussão, mas o envolvimento das diferentes orientações sexuais presentes na produção desses espetáculos e que vigoram o espaço de pertencimento dentro do campo de produção cultural.

Esse movimento de luta vivenciado por mulheres hetero/homo no jogo de poder da sociedade, expresso fortemente por uma masculinidade heteronormativa, precisa ser debatido também na perspectiva do teatro LGBT. Para tanto, este artigo apresenta uma reflexão sobre as disputas internas, em decorrência das diferentes identidades de gênero, e externas mediante ao campo do teatro LGBT e as tensões com os campos da economia, política e religião, tendo como abordagem teórica o conceito de campo do sociólogo Pierre Bourdieu. Logo, apresenta-se como estudo de caso o conjunto de 22 peças de teatro com temáticas LGBT, que ficaram em cartaz durante o período que antecedeu a Parada do Orgulho LGBT 2018, evento anual que acontece na Avenida Paulista, cidade de São Paulo/SP e que, em decorrência desta festividade, oferece um leque de atrações culturais voltadas à este segmento.

Para a análise da cadeia de produção de trabalho apresenta-se a abordagem exploratória/comparativa entre as orientações sexuais presentes em etapas do desenvolvimento dos espetáculos, com base em fichas técnicas disponíveis no Guia Gay São Paulo, site para divulgação de entretenimento do segmento LGBT, utilizando-se como referência o teatro LGBT realizado na cidade de São Paulo/SP. 


\section{CAMPO COMO ESPAÇO DE DISPUTAS NA PRODUÇÃO CULTURAL}

Para debater as relações de poder vigentes no teatro LGBT é preciso analisar os confrontos internos existentes em seu campo simbólico referente às identidades representadas pela sigla LGBT. “Em um campo como o campo político ou o campo religioso, ou qualquer outro campo, as condutas dos agentes são determinadas por sua posição na estrutura da relação de forças característica desse campo no momento considerado" (BOURDIEU, 2011, p. 201). A hegemonia gay e trans dentro do campo do teatro LGBT evidencia que "a relação que o criador mantém com a sua obra, e a própria obra são afetadas pelo sistema de relações sociais nas quais se realiza a criação como ato de comunicação, ou mais precisamente, pela posição do criador na estrutura do campo intelectual” (BOURDIEU, 1968, p.105). Nesse sentido, a criação das obras teatrais LGBT são um reflexo das temáticas vigentes na sociedade brasileira. Ao mesmo tempo, essa posição dos artistas gays e trans, cuja maioria dos espetáculos LGBT representam essas identidades, ressalta que o "produtor do valor da obra de arte não é o artista, mas o campo de produção enquanto universo de crença que produz o valor da obra de arte como fetiche ao produzir a crença no poder criador do artista" (BOURDIEU, 1992, p. 259).

Esse campo de produção aparenta trazer o valor da obra LGBT em sua totalidade, ou seja, quando se lê em um guia cultural sobre uma mostra de peças LGBT, espera-se encontrar todas as letras dessa sigla representadas em cena. Entretanto, "nessa dinâmica, aqueles que contam com certo monopólio do capital legitimado no campo têm maiores possibilidades de serem atendidos em suas opiniões e escolhas" (PEREIRA, 2015, p. 348).

No campo do teatro LGBT, ainda que existam mulheres hetero e homosexuais na cadeia de produção dos espetáculos, como é possível observar nas fichas técnicas de diferentes peças homoafetivas disponíveis em guias culturais, a identidade lésbica não está representada nas temáticas dos referidos espetáculos. Logo, a autenticação dessas produções de cunho gaye trans em São Paulo faz parte da tomada de posição dos agentes hegemônicos dentro do campo.

A depender da posição que ocupam na estrutura do campo, ou seja, na distribuição do capital simbólico específico, os agentes usam de estratégias, que são tomadas de posição, que podem ser de legitimação (conservação) ou de subversão, estas em confronto permanente com as forças de conservação - o que não implica em mudanças dos princípios de poder que estruturam um campo (LIMA, 2010, p. 16).

Entre as relações de poder vigentes dentro do campo do teatro LGBT, se faz presente a conservação de uma tomada de posição que legitima a masculinidade nas artes. Essa tomada de posição também é manifestada nas disputas da cadeia de produção cultural, nos aspectos que envolvem desde a dramaturgia e criação dos textos, na direção dos espetáculos, nas diferentes funções de cenografia, figurinista, aderecista, produtor musical, preparador de elenco até a divulgação das peças por meio de assessores de imprensa, jornalistas, guias culturais e publicidade, bem como na relação com 
o público. Em todas essas esferas, a forma binária homem/ mulher se faz presente, com um número reduzido da participação de mulheres hetero/homo dentro desses espaços de produção cultural.

Além dos aspectos que envolvem as disputas internas, o campo do teatro LGBT também está em disputa com outros campos, já que a dimensão da cultura, com devida autonomia, não tem o mesmo peso que a política e a economia. Nesse sentido, tratando-se do mercado LGBT, o estudo Out Leadership aponta para um potencial de consumo de US\$ 133 bilhões, o que equivale a R\$ 418,9 bilhões - ou $10 \%$ do Produto Interno Bruto (PIB) (CARDOSO, 2017).

Esse cenário apresenta-se porque "a renda elevada se explica pelas classes sociais em que estão inseridos: $36 \%$ pertencem a A e $47 \%$ a B” (OLIVEIRA e SILVA, 2017, p.2). Logo, este aspecto mercadológico tem o seu reflexo no setor da cultura para atender aos anseios de consumo do público LGBT.

Outro campo que está em tensão com a produção teatral em geral é o político, por meio de companhias teatrais que se posicionam politicamente ao realizar um teatro de crítica social.

Mais do que a busca por uma igualdade de distribuição de verba equânime entre os integrantes, o financiamento das companhias está diretamente relacionado com o posicionamento político dos grupos e também com a visão das companhias sobre o seu papel na produção artística (AOKI, 2017, p. 77).

Embora exista uma produção que atenda à elite econômica, orientada ao mercado, a exemplo dos musicais, as políticas públicas voltadas ao incentivo à cultura são subsídios de apoio a muitas companhias de teatro paulistanas que mantém trabalhos de pesquisa cênica com as referidas verbas disponíveis, a exemplo da Lei Municipal do Fomento ao Teatro, com a proposta de um trabalho de continuidade.

Há uma convergência na opinião das companhias de que é necessário o incentivo do Estado para que o tipo de arte produzida seja possível. Os grupos consideram que praticam uma "arte pública" e que seu financiamento, também público, pode garantir a autonomia do pensamento artístico" (Ibidem, p. 77).

Aqui, a Arte Social se faz presente em oposição à Arte Industrial que "é também uma indústria artística capaz de explorar economicamente o trabalho dos artistas porque é uma instância de consagração que governa a produção dos escritores e artistas” (BOURDIEU,1996, p. 22). Entretanto, “a Arte Industrial oferece um lugar de encontro a artistas que ocupam posições opostas, partidários da 'arte social', defensores da arte pela arte ou escritores consagrados pelo público burguês” (ibidem, p. 22).

Desse modo, os campos econômico e político estão em constante tensão com o campo do teatro LGBT, por meio das questões mercadológicas e de cunho militante. Todavia, outros campos também estão em disputa no teatro, como o poder judiciário, com a proibição do espetáculo "O Evangelho Segundo Jesus, Rainha do Céu”, que seria exibido no segundo semestre de 2017 em Salvador/BA. Nesse sentido, o campo religioso também está em disputa, já que esta decisão da proibição da peça atende a interesses religiosos de cunho judaico-cristão, representados também no campo da política.

Pierre Bourdieu (2005) ressalta que: 
A estrutura das relações entre o campo religioso e o campo do poder comanda, em cada conjuntura, a configuração das estruturas das relações constitutivas do campo religioso que cumpre uma função externa de legitimação da ordem estabelecida na medida em que a manutenção da ordem política, ao passo que a subversão simbólica da ordem simbólica só consegue afetar a ordem política quando se faz acompanhar por uma subversão política desta ordem (BOURDIEU, 2005, p. 69).

Ao considerar que os campos econômico, político e religioso estão em tensão com o campo do teatro LGBT, vê-se que esta estrutura vai sendo modificada na forma interna do campo, conforme as disputas vão acontecendo. Essas mudanças fazem parte dos confrontos por legitimidade e que também estão relacionadas com as formas de produção que envolvem a estrutura Estado versus Indústria Cultural:

[...] o teatro comercial sobrevive hoje através de três modalidade: as 'versões francesas de empreendimentos estrangeiros, supervisionados, distribuídos e, em parte, comandados pelos responsáveis pelo espetáculo original' (nos moldes importados da indústria cinematográfica e do music-hall), as reprises das obras mais consagradas do teatro de boulevard tradicional e, por último, 'a comédia inteligente para a burguesia esclarecida'. Por sua vez, o teatro não-comercial compõe-se, de um lado, pelos teatros subvencionados cujas pesquisas estéticas e escolhas ideológicas devem sua independência relativa à situação economicamente artificial que lhes assegura a ajuda econômica do Estado e, de outro, pelos teatros de vanguarda fadados a incertezas vertiginosas da marginalidade (/bidem, p.138).

Mesmo que Bourdieu cite as versões francesas de empreendimentos, a indústria cultural brasileira aposta nas produções da Broadway em grandes salas de teatro da cidade de São Paulo, a exemplo de espetáculos “O Fantasma da Ópera”, que ficou em cartaz no primeiro semestre de 2018, no Teatro Bradesco. Já as "comédias inteligentes" fazem parte das diferentes salas de teatro da grande capital para atender ao público que está em busca do entretenimento.

Alguns espetáculos LGBT transitam entre o teatro comercial e o não-comercial. Em relação às produções que recebem ajuda do Estado, embora existam leis vigentes de incentivo, cortes na pasta da cultura influenciam nos trabalhos de continuidade realizados por diferentes grupos teatrais.

Do ponto de vista das práticas mercadológicas, o teatro LGBT tem utilizado eventos como a Parada do Orgulho LGBT para dar visibilidade e atrair o público para essas produções. Somente no ano de 2017, durante as semanas que antecedem o evento, 19 peças ficaram em cartaz na cidade de São Paulo/SP. Em comparação com 2018, o número aumentou para 22 espetáculos. Aqui o campo econômico está em disputa com o campo do teatro LGBT ao inserir as produções culturais como práticas de lazer voltadas ao evento, enquanto o teatro LGBT busca contribuir para a visibilidade do grupo por meio da militância, embora para legitimar o poder hegemônico das identidades de gênero dominantes em cena e no campo social, em detrimento dos demais. 


\section{TEATRO LGBT NA CIDADE DE SÃO PAULO}

Para a compreensão da atuação do binarismo homem/mulher na cadeia de produção cultural do teatro LGBT paulistano, por meio do método exploratório/comparativo, de cunho quantitativo, apresentam-se dados de 22 espetáculos teatrais encenados em 2018 que foram divulgados pelo Guia Gay São Paulo, disponível na versão online. Esta metodologia permite relacionar a quantidade de homens/mulheres cis e mulher trans em diferentes posições de atuação. Nesse sentido, para diferenciar mulher cisgênero ${ }^{2}$ e mulher transexual, além do que aparece no guia, os nomes foram consultados na plataforma Google.

Na tabela 1, é possível observar dados como nome dos espetáculos, quem escreveu os textos, a direção e atores que participaram da encenação:

Tabela 1 - Informações sobre os espetáculos

\begin{tabular}{|c|c|c|c|}
\hline Espetáculo & Texto & Direção & Elenco \\
\hline A Banheira & Gugu Keller & Não informado & $\begin{array}{l}\text { Du Kammargo, Beto Schultz, } \\
\text { Carol Hubner, Reginaldo Faidi } \\
\text { e Carolina Stofella }\end{array}$ \\
\hline $\begin{array}{l}\text { A Cigarra e a } \\
\text { Formiga }\end{array}$ & Ricardo Leitte & Ricardo Leitte & $\begin{array}{c}\text { Valenttine, Alexia Twister e } \\
\text { Ricardo Leitte }\end{array}$ \\
\hline $\begin{array}{l}\text { Acredite, Um } \\
\text { Espírito Baixou } \\
\text { em Mim }\end{array}$ & $\begin{array}{l}\text { Ronaldo Ciam- } \\
\text { broni }\end{array}$ & $\begin{array}{c}\text { Sandra Pêra } \\
\text { Manoelita Lustosa (assis- } \\
\text { tente de direção) }\end{array}$ & $\begin{array}{l}\text { Ilvio Amaral, Maurício Can- } \\
\text { guçu, Adriana Ferrari, Bruno } \\
\text { Albertini e Marino Canguçu }\end{array}$ \\
\hline $\begin{array}{c}\text { Rose, a Doméstica } \\
\text { do Brasil }\end{array}$ & Lindsay Paulino & Adriana Soares & Lindsay Paulino \\
\hline Elas São Lokas & Não informado & Não informado & $\begin{array}{c}\text { Dicesar Ferreira (Dimmy Kieer), } \\
\text { Kaká de Lima, Stefany Di Bour- } \\
\text { bon, Ingrid Bryam, Roberson } \\
\text { Lima (Mulher Tudão) e Luisa } \\
\text { Marilac. }\end{array}$ \\
\hline $\begin{array}{l}\text { Eu Sou Ela, Ela } \\
\text { Sou Eu }\end{array}$ & Dicesar Ferreira & $\begin{array}{c}\text { Marcelo Mendes } \\
\text { DJ Guto Rodrigues (Dire- } \\
\text { ção Musical) }\end{array}$ & Dicesar Ferreira \\
\hline
\end{tabular}

2 Quando uma pessoa se identifica com o gênero que foi designado a ela ao nascer. 


\begin{tabular}{|c|c|c|c|}
\hline Espetáculo & Texto & Direção & Elenco \\
\hline $\begin{array}{c}\text { A Princesa e a } \\
\text { Costureira }\end{array}$ & Solange Dias & Antonio Correia Neto & $\begin{array}{c}\text { Erika Coracini, Marcio Ribeiro e } \\
\text { Mariana Sancar }\end{array}$ \\
\hline Querido Amigo & $\begin{array}{l}\text { Gustavo Vierling e } \\
\text { Thiago Mantovani }\end{array}$ & $\begin{array}{l}\text { Ivo Ueter (Direção Geral) } \\
\text { Filipe Bertini } \\
\text { (Direção Executiva) }\end{array}$ & $\begin{array}{c}\text { Filipe Bertini, Ivo Ueter, Klaus } \\
\text { Hee e Yago Senciane }\end{array}$ \\
\hline Vidros Arriados & Antonio Ranieri & Marcio Macena & $\begin{array}{c}\text { Antonio Ranieri e Rogério } \\
\text { Mendes }\end{array}$ \\
\hline $\begin{array}{l}\text { O Vlogger Hipster } \\
\text { do Grindr - O } \\
\text { Musical }\end{array}$ & Alexandre Biondi. & $\begin{array}{l}\text { Alexandre Biondi (Direção } \\
\text { Geral) } \\
\text { Ivy Garcia e Léo Lima } \\
\text { (Direção Musical) }\end{array}$ & $\begin{array}{l}\text { Evando Lustosa, Gustavo } \\
\text { Medeiros, Ivy Garcia, Marcos } \\
\text { Razec, Monique Almeida, } \\
\text { Rafael Braga, Rodrigo Sotero e } \\
\text { Vinícius Milhomem }\end{array}$ \\
\hline $\begin{array}{c}\text { Coisas Estranhas } \\
\text { Acontecem Nesta } \\
\text { Casa }\end{array}$ & $\begin{array}{c}\text { Pablo Diego } \\
\text { Garcia }\end{array}$ & $\begin{array}{c}\text { Marcio Macena } \\
\text { Marisa Orth (Codireção) }\end{array}$ & $\begin{array}{c}\text { Almir Martins, Bruno Speran- } \\
\text { ça, Daniel Aguiar, Deo Patrício, } \\
\text { Pablo Diego Garcia. }\end{array}$ \\
\hline Dama da Noite & Não Informado & André Leahun & Luiz Fernando Almeida \\
\hline $\begin{array}{l}\text { Eu Sei Exatamen- } \\
\text { te Como Você Se } \\
\text { Sente }\end{array}$ & $\begin{array}{l}\text { Neil Bartlett } \\
\text { Tradução: Fernan- } \\
\text { da Maia, Samya } \\
\text { Peruchi e Zé Hen- } \\
\text { rique de Paula. }\end{array}$ & $\begin{array}{c}\text { Inês Aranha e Zé Henri- } \\
\text { que de Paula. }\end{array}$ & $\begin{array}{c}\text { Fabio Redkowicz, Paulo Olyva, } \\
\text { Pedro Silveira e Zé Henrique de } \\
\text { Paula. }\end{array}$ \\
\hline $\begin{array}{l}\text { Guarde para os } \\
\text { Dias de Chuva }\end{array}$ & $\begin{array}{l}\text { Júlio César Ada- } \\
\text { manto. }\end{array}$ & $\begin{array}{l}\text { Júlio César Adamanto } \\
\text { Alexandre Biondi (Direção } \\
\text { de elenco) }\end{array}$ & $\begin{array}{l}\text { Rodrigo Rope, Fabio Viecelli, } \\
\text { Glau Gurgel, Priscila Casari, } \\
\text { Klever Ravanelli e Rita Lopes }\end{array}$ \\
\hline $\begin{array}{l}\text { Somos Todos Tão } \\
\text { Jovens }\end{array}$ & $\begin{array}{l}\text { Vinícius de Oli- } \\
\text { veira }\end{array}$ & $\begin{array}{c}\text { Ricardo Grasson } \\
\text { Alexandre Biondi (Direção } \\
\text { Assistente) }\end{array}$ & $\begin{array}{c}\text { Ghilherme Lobo, Júlio Oliveira, } \\
\text { Gabriel Moura, Bruno Damá- } \\
\text { sio, Fernando Burack e Luis } \\
\text { Fernando Delalibera. Alternan- } \\
\text { tes Eventuais - Danillo Branco, } \\
\text { Lucas Miagusuku e Rafael } \\
\text { Barbosa. }\end{array}$ \\
\hline
\end{tabular}




\begin{tabular}{|c|c|c|c|}
\hline Espetáculo & Texto & Direção & Elenco \\
\hline Bruta Flor & $\begin{array}{l}\text { Vitor de Oliveira e } \\
\text { Carlos Fernando } \\
\text { de Barros }\end{array}$ & Marcio Rosario & $\begin{array}{l}\text { André Pottes, Fernando Zilli e } \\
\text { Carol Marra }\end{array}$ \\
\hline $\begin{array}{c}\text { O Rapaz da Rua } \\
\text { Augusta }\end{array}$ & Roberto Freitas & Roberto Freitas & $\begin{array}{l}\text { Bruno Alba, Danilo Branco, } \\
\text { Kainan Ferraz e Raphael Falcão } \\
\text { (revezando). }\end{array}$ \\
\hline $\begin{array}{l}\text { Sabe Quem } \\
\text { Dançou? }\end{array}$ & Zeno Wilde & Hermes Carpes & $\begin{array}{l}\text { Hermes Carpes, Ronaldo } \\
\text { Spedaletti, André Melo e Jean } \\
\text { Coué }\end{array}$ \\
\hline $\begin{array}{c}\text { As } 3 \text { Uiaras de SP } \\
\text { City }\end{array}$ & Ave Terrena Alves & Diego Moschkovich. & $\begin{array}{l}\text { Danna Lisboa, Diego Chilio, } \\
\text { Maria Emília Faganello, Sophia } \\
\text { Castellano e Verônica Valent- } \\
\text { tino. }\end{array}$ \\
\hline $\begin{array}{l}\text { Cabaret Transpe- } \\
\text { ripatético }\end{array}$ & $\begin{array}{l}\text { Dramaturgia } \\
\text { coletiva }\end{array}$ & Rodolfo García Vázquez & $\begin{array}{c}\text { Daniela Funez, Fernanda } \\
\text { Kawani, Gabriel Lodi, Guttervil, } \\
\text { João Henrique Machado, Léo } \\
\text { Perisatto, Luh Maza e Sofia } \\
\text { Riccardi. }\end{array}$ \\
\hline Motel Marques & Casé Proença & Casé Proença & $\begin{array}{l}\text { Edson Rocha, Luciano Rocha, } \\
\text { Fernando Negah e Mário Góes }\end{array}$ \\
\hline Pink Star & $\begin{array}{l}\text { Ivam Cabral e } \\
\text { Rodolfo García } \\
\text { Vázquez, }\end{array}$ & Não informado & $\begin{array}{l}\text { Artistas de várias identidades } \\
\text { de gênero - cisgêneros, trans- } \\
\text { gêneros, agêneros e não biná- } \\
\text { rios - e orientações sexuais - } \\
\text { heterossexuais, homossexuais, } \\
\text { demissexuais e bissexuais }\end{array}$ \\
\hline
\end{tabular}

Fonte: Elaborado pelos autores (2018)

Além dos nomes das peças, foram escolhidos somente os itens: texto, direção e elenco. Isso porque o guia cultural não disponibiliza, para todos os espetáculos, as mesmas informações. Há peças com ficha técnica completa, a exemplo de produtores e assessores de imprensa, enquanto outras, dispõe de informações básicas. Ademais, os itens escolhidos trazem uma mostra possível para efeito de comparação entre os dados. 


\section{CORRELAÇÃO ENTRE AS DIFERENTES IDENTIDADES}

Entre os dados coletados das 22 peças teatrais LGBT, apresenta-se na tabela abaixo a quantidade de textos produzidos:

Tabela 2 - Textos de teatro LGBT

\begin{tabular}{|c|c|}
\hline Textos produzidos por homens & Textos produzidos por mulheres \\
\hline 21 & 1 \\
\hline
\end{tabular}

Fonte: Elaborado pelos autores (2018)

Sobre a quantidade de diretores (as) envolvidos com as peças:

Tabela 3 - Direção dos espetáculos

\begin{tabular}{|c|c|}
\hline Diretores & Diretoras \\
\hline 23 & 4 \\
\hline
\end{tabular}

Fonte: Elaborado pelos autores (2018)

O elenco participante das produções teatrais está dividido entre três grupos:

Tabela 4 - Elenco dos espetáculos LGBT

\begin{tabular}{|c|c|c|}
\hline Atores & Atrizes & Transgênero \\
\hline 63 & 15 & 12 \\
\hline
\end{tabular}

Fonte: Elaborado pelos autores (2018)

Embora os espetáculos sejam LGBT, o guia cultural não disponibiliza informações sobre a orientação sexual dos produtores culturais. Logo, pela análise dos nomes é possível observar a hegemonia masculina em detrimento das mulheres cisgênero e transexuais. A quantidade de homens nas três esferas da cadeia de produção (dramaturgos, diretores e atores) resultou em 107, enquanto as mulheres constituem apenas 20 indivíduos e mulheres transexuais, somente 12. Outro dado relevante está relacionado às sinopses dos espetáculos. Ainda que não apareçam nas tabelas, consultadas no guia, revelam temáticas relacionadas ao universo gay e trans, fato este que dialoga com as questões do campo econômico, já que o público gay é consideravelmente rentável dentro da perspectiva mercadológica. Logo, é possível considerar que a tensão entre o campo econômico e o teatro LGBT favorece a tomada de posição de gays em detrimento das mulheres hetero/homo. 
Por esta perspectiva, os campos político e religioso não contribuem com a tomada de posição das mulheres, seja pela falta de criação de editais voltados à ocupação de maiores espaços, seja pela questão da condição da mulher considerada como inferior à masculinidade vigente.

\section{CONSIDERAÇÕES FINAIS}

A hegemonia masculina na cadeia de produção cultural demonstra que as mulheres hetero/homossexuais têm ocupado poucos espaços de pertencimento dentro do campo do teatro LGBT, fato este que valida fatores de repressão social a exemplo de misoginia e o machismo reproduzidos também na esfera da arte. A quantidade apresentada de textos, direção e elenco revelam que homens ocupam esse espaço para retratar os conflitos das práticas homoeróticas masculinas, decorrentes de uma organização gay, fato este que acontece tanto na sociedade quanto dentro do teatro.

Do ponto de vista da estrutura do campo, a masculinidade mantém a tomada de posição, embora trabalhos esporádicos, com temáticas lésbicas, apareçam algumas poucas vezes nos guias culturais ao longo do ano. Mesmo que exista um levante dos movimentos feministas no início do século XXI, ainda não há uma ocupação de espaços na cadeia de produção cultural do teatro LGBT equiparada aos homens, mesmo durante eventos como a Parada LGBT, cujas produções teatrais representam o público hegemônico do evento. Nesse sentido, abrem-se novas possibilidades para a reflexão e caminhos que retratam esta problematização ao levar a outras perspectivas, a exemplo da busca por textos produzidos por mulheres, com temáticas da lesbianidade, e que possam estar adormecidos, designando, assim, potenciais produções capazes de causas possíveis transformações no campo de forças para que novas tomadas de posição sejam feitas por mulheres através da luta por ocupação de espaços e direitos equiparados na cadeia de produção cultural do teatro LGBT .

\section{REFERÊNCIAS}

AOKI, Thiago Barbosa. Existência e Resistência: o Teatro Militante paulistano. Instituto de Filosofia e Ciências Humanas, UNICAMP. 2017. Disponível em: <http://repositorio.unicamp.br/bitstream/ REPOSIP/322695/1/Aoki_ThiagoBarbosa_M.pdf> Consultado em: 22/07/2018.

BOURDIEU, Pierre. Problemas do Estruturalismo. Rio de Janeiro, Zahar Editores, 1968.

BOURDIEU, Pierre. O ponto de vista do autor: algumas propriedades gerais dos campos de produção cultural. In: BOURDIEU, Pierre. As regras da arte: gênese e estrutura do campo literário. São Paulo: Companhia das Letras, 1992. p. 243-316. 
BOURDIEU, Pierre. As regras da arte: Gênese e estrutura do campo literário. Ed.2, Companhia das Letras, 1996.

BOURDIEU, Pierre. A economia das trocas simbólicas. Ed. 6, Perspectiva, 2005.

BOURDIEU, Pierre. O campo político. Revista Brasileira de Ciência Política. n.5 Brasília Jan./July 2011

BOURDIEU, Pierre. Os usos sociais da ciência: por uma sociologia clínica do campo científico. São Paulo: UNESP, 2004.

BRADESCO, Teatro. A Bela e a Fera. Disponível em: <https://www.teatrobradesco.com.br/ programacao.php?id=852_A+BELA+E+A+FERA>Acesso em: 22/07/2018.

CARDOSO, Fábio. Potencial de consumo do segmento LGBT no Brasil gira em torno de US\$ 133 bilhões. Turismo em Foco. Disponível em: <http://www.turismoemfoco.com.br/v2017/2017/07/23/ potencial-de-consumo-do-segmento-lgbt-no-brasil-gira-em-torno-de-us-133-bilhoes/> Acesso em: 22/07/2018.

GAY, Guia. 22 peças de temática LGBT estão em cartaz na semana da Parada. Disponível em: <http://www.guiagaysaopaulo.com.br/noticias/cultura/22-pecas-de-tematica-lgbt-estao-emcartaz-na-semana-da-parada> Acesso em: 24/07/2018.

GAY, Gui. Para aplaudir! SP tem 19 peças LGBT na semana da Parada. Disponível em: <http:// www.guiagaysaopaulo.com.br/noticias/cultura/para-aplaudir!-sp-tem-pecas-lgbt-na-semana-daparada!> Acesso em: 24/07/2018.

G1. Peça teatral que retrata Jesus como mulher trans é vetada em Salvador por decisão da justiça. G1 Rede Bahia. Disponível em: <https://g1.globo.com/bahia/noticia/peca-teatral-que-retrata-jesuscomo-mulher-trans-e-vetada-em-salvador-por-decisao-da-justica.ghtml> Acesso em: 22/07/2018.

LIMA, Denise Maria de Oliveira. Campo do poder, segundo Pierre Bourdieu. Cógito, Salvador, n.11 p. $14-19 \cdot$ Outubro. 2010

OLIVEIRA, Vânia Braz, SILVA, Márcio Augusto M. da. Empresas e marcas se voltam para a causa LGBT. Ciência que Aproxima, Ciência que Liberta. UNIVAP. 2017. Disponível em: <http://www. inicepg.univap.br/cd/INIC_2017/anais/arquivos/RE_0882_0519_01.pdf> Acesso em: 22/07/2018.

PEREIRA, Elaine Aparecida Teixeira. O conceito de campo de Pierre Bourdieu: possibilidade de análise para pesquisas em história da educação brasileira. Revista Linhas. Florianópolis, v. 16, n. 32, p. 337 - 356, set./dez. 2015. 
RESENDE, Roberta. EPITÁCIO, Sara. A luta das mulheres pelo "Espaço Público": Notas sobre o caso do Brasil. Interfaces Científicas - Direito, Aracaju , V.5, N.3, p. 61 - 72, Jun. 2017.

SÃO PAULO, Prefeitura. Lei do Fomento ao Teatro. Disponível em: <http://www.prefeitura.sp.gov.br/ cidade/secretarias/cultura/noticias/?p=7298> Acesso em: 24/07/2018.

1 Mestranda no Programa Interdisciplinar em Estudo Culturais na Escola de Artes, Ciências e Humanidades da Universidade de São Paulo - EACH USP - São Paulo, Brasil. Graduada em Comunicação Social - Jornalismo pela Universidade Paulista - UNIP. camilagrillo@usp.br

2 Professor Dr. ligado aos programas de pós-graduação na Escola de Artes, Ciências e Humanidades, Universidade de São Paulo - EACH/USP, São Paulo, São Paulo, Brasil e Universidade Federal do Rio Grande do Norte - UFRN, Natal, Rio Grande do Norte, Brasil. ricardolanzarini@ccsa.ufrn.b

\section{(). (1) (2)}

Este artigo é licenciado na modalidade acesso abertosob a Atribuição-Compartilhalgual CC BY-SA

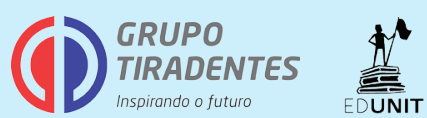


